\title{
Nasal airflow of patient with septal deviation and allergy rhinitis
}

\author{
Zi Fen Lim ${ }^{1}$ Parvathy Rajendran ${ }^{1,2^{*}}$, Muhamad Yusri Musa ${ }^{3}$ and Chih Fang Lee ${ }^{1}$
}

\begin{abstract}
A numerical simulation of a patient's nasal airflow was developed via computational fluid dynamics. Accordingly, computerized tomography scans of a patient with septal deviation and allergic rhinitis were obtained. The threedimensional (3D) nasal model was designed using InVesalius 3.0, which was then imported to (computer aided 3D interactive application) CATIA V5 for modification, and finally to analysis system (ANSYS) flow oriented logistics upgrade for enterprise networks (FLUENT) to obtain the numerical solution. The velocity contours of the cross-sectional area were analyzed on four main surfaces: the vestibule, nasal valve, middle turbinate, and nasopharynx. The pressure and velocity characteristics were assessed at both laminar and turbulent mass flow rates for both the standardized and the patient's model nasal cavity. The developed model of the patient is approximately half the size of the standardized model; hence, its velocity was approximately two times more than that of the standardized model.
\end{abstract}

Keywords: Three-dimensional nasal airflow model, Septal deviation, Allergy rhinitis, Computational fluid dynamics

\section{Introduction}

The nasal cavity is one of the most critical parts of the human respiratory system [1-3]. Nasal obstructions, such as nasal septum deviations, enlarged turbinates, nasal polyps, enlarged adenoids, tumors, and nasal congestion, can trigger breathing difficulties. In this study, two major nasal obstructions are considered: septal deviation and allergic rhinitis.

The nasal septum is the bone that divides one side of the nose from the other. It is rarely perfectly straight, and it is comprises a central supporting skeleton covered on each side by mucous membranes $[4,5]$. The front part of this natural partition is a firm but bendable structure, made mostly of cartilage and covered by skin with a substantial supply of blood vessels. In addition, it is slightly crooked in over $80 \%$ of people [6].

When the septum is crooked or deviated, it blocks nasal passage, and a surgical operation, submucosal resection, is required to restore clear breathing. Septal deviations play

\footnotetext{
* Correspondence: aeparvathy@usm.my

${ }^{1}$ School of Aerospace Engineering, Universiti Sains Malaysia, 11800 Pulau

Pinang, Malaysia

${ }^{2}$ Faculty of Engineering \& Computing, First City University College, 47800

Selangor, Malaysia

Full list of author information is available at the end of the article
}

a critical role in nasal obstruction symptoms, the aesthetic appearance of the nose, increased nasal resistance, and sometimes snoring [7]. Symptoms of a deviated septum include sinus infections, sleep apnea, snoring, repetitive sneezing, facial pain, nosebleeds, and difficulty with breathing, as well as mild to severe loss of smell [8].

Rhinitis is defined as an inflammation of the nasal mucosa, which affects approximately $40 \%$ of the population [9-11]. Allergic rhinitis is the most common cause of mucosal inflammation, and it affects one in six individuals [12]. There are two types of allergic rhinitis: seasonal and perennial. Seasonal allergic rhinitis can occur in spring, summer, and early fall. It is usually caused by allergic sensitivity to airborne mold spores or pollen from grass, trees, and weeds. Allergy rhinitis is estimated to affect nearly one in every six Americans, and generates $\$ 2$ to $\$ 5$ billion in direct health expenditures annually [12].

To better understand the physiology of the nasal cavity, this study adopts the computational fluid dynamics (CFD) method to obtain and compare flow patterns. Hence, CFD has become a fast and convenient research tool for studying airflow in the human airway, especially when investigating heat and humidity transfer, which is difficult to investigate with other experimental techniques [13-16]. 
CFD simulations help to better understand the complex anatomy of the nasal, as well as the implications of disease and surgery. It has the potential to help surgeons and rhinologists plan surgery and simulate surgery by correcting perceived anatomical abnormalities on a model called "virtual surgery" and then comparing flow predictions to help surgeons and rhinologists decide whether minor or major corrective surgery is needed [17]. Hence, CFD simulation findings, such as cross-sectional areas, velocity magnitudes, contours, and streamlines, can be examined in detail, allowing for improvements and corrections if there are any inadequacies or insufficiencies in information for rhinologists as a pre-operative tool to aid in clinical decision making.

In this study, the computerized tomography (CT) scans of a female adult patient with septal deviation and allergic rhinitis were obtained with consent from the Advanced Medical and Dental Institute, University of Science Malaysia. The three-dimensional (3D) model of the nasal cavity was developed from CT scans and exported to CATIA V5, and then airflow simulation was performed. To analyze the impact of septal deviation and allergic rhinitis on nasal airflow, the obtained results will be compared with a standardized nasal cavity.

\section{Methods}

CFD can predict airflow and particle deposition in the nasal cavity [11, 18-21]; hence, it is widely used in the airflow prediction of complex structures. In this case, FLUENT was adopted for the simulation to obtain an accurate airflow simulation of the patient's nasal cavity. To determine the impact of septal deviation and allergic rhinitis, the CFD results of fluid mechanical properties were then analyzed and compared with the standardized nasal cavity model of a health female adult.

\section{Model reconstruction}

InVesalius 3.0 is an open-source software for virtual modeling, and it can obtain an accurate model of the anatomical region to be studied, as high-quality medical images are necessary [22]. The digital imaging and communications in medicine files of a female patient were imported into the InVesalius 3.0. The number of twodimensional (2D) slices in three axes is presented in Table 1. Because this study focused solely on the nasal cavity, the number of slices that did not involve the nasal cavity was not considered.

An inverted model of the patient's airway was constructed by filling the space in which the air flows, including the 2D slices mentioned in Table 1 . The reconstructed airway of the subject can be visualized using this software. Then, the model was exported as a STL file and imported into CATIA V5 as the cloud point. The model was then smoothened and modified
Table 1 Number of 2D slices for CT scans of patient

\begin{tabular}{lll}
\hline Axis & Total number of slices & Number of slices used \\
\hline Axial & 238 & $103-171$ \\
Coronal & 511 & $216-427$ \\
Sagittal & 511 & $215-301$ \\
\hline
\end{tabular}

after mesh creation in CATIA. Surface and volume creation will also be performed in CATIA to reconstruct a solid model. Then, the 3D model saved as a STEP file was imported into ANSYS FLUENT for simulation.

\section{Simulation}

The nasal wall was assumed to be rigid, with a no-slip boundary condition, and mucous effects were assumed to be negligible $[23,24]$. The nostril inlet is defined by the mass flow inlet, while the outflow boundary condition represents the outlet at the nasopharynx. Any backflow at the outlet was assumed to be at $32.6{ }^{\circ} \mathrm{C}$, and $100 \%$ relative humidity was imported into ANSYS FLUENT [15]. The pressure-based model was adopted for this simulation, as the density of air was assumed to be constant throughout the geometry [25]. The flow of mucus was not considered owing to its minimal thickness and low velocity $[23,26]$. The mesh models of the three meshing types for the mesh dependency study (Fig. 1) and its model elements are presented in Table 2.

The accuracy of the numerical results is closely related to the mesh density, as well as its distribution. Therefore, the mesh plays a significant role in the outcome of numerical simulations [10, 27]. A functional mesh must be able to resolve the velocity vectors and effectively capture the fluid properties in all regions inside the nasal cavity [28, 29]. After the mesh dependency study, a simulation was performed for the medium meshed model in ANSYS FLUENT. The mesh dependency study exhibited an optimized meshing of 7,814,330 elements. The model was adopted for mass flow rates ranging from $100 \mathrm{~mL} / \mathrm{s}$ to $425 \mathrm{~mL} / \mathrm{s}$, as the inspiratory flow rate for healthy adults is varied between $80 \mathrm{~mL} / \mathrm{s}$ and $200 \mathrm{~mL} / \mathrm{s}$ for light breathing and a range of $200-660 \mathrm{~mL} / \mathrm{s}$ for nonnormal conditions such as during exercises [30].

\section{Results}

The results obtained from the simulation are presented and discussed in three sections. The Geometrical comparisons section presents a geometrical comparison of two nasal cavity models: the current study with the female adult-patient model and the standardized female adult model generated by Lee et al. [31] in their previous research. In this section, the comparison is performed via the visual 


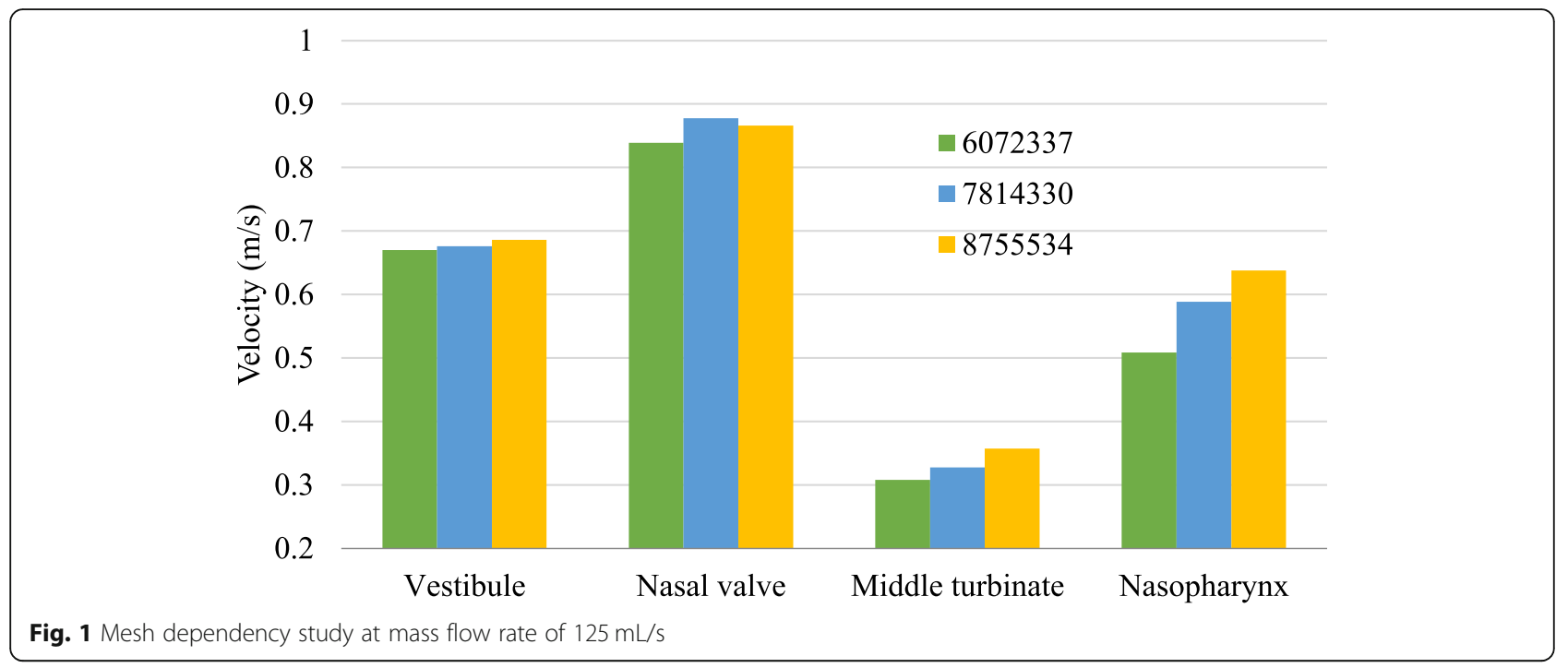

observation of both the 3D nasal cavity models and their cross-sectional areas at different planes. The Pressure section focuses on the pressure at different planes with varying mass flow rates, and the decrease in pressure of the nasal model. The Velocity section then compares both models, including the velocity magnitude in different planes and graphical results obtained from the CFD analysis, as well as the velocity contour of both models.

\section{Geometrical comparisons}

Respiratory physiology and pathology significantly depend on the airflow inside the nasal cavity. Because nasal airflow is profoundly affected by the geometry of the flow passage, changes in the shape of the nasal cavity due to diseases or surgical treatments alter the nasal resistance and functions of the nose [32-35]. Geometric configuration plays a significant role in the flow distribution inside the nasal cavity, especially in disease cases, as the imbalance of the nasal cavity owing to septal deviation is considered to be a common etiology of nasal airway obstruction $[4,13,16]$. The geometric comparisons of the 3D models are presented in Table 3.

As presented in Table 3, the model of the patient's nasal cavity exhibits several disconnections that cause difficulties in breathing $[15,36]$. In addition, the crosssection of the middle turbinate significantly differs from the standardized model in size, and the standardized model has a smoother and cleaner airway than that of the patient's model. The patient's model shows many creases on the surface as there are several growths in the nasal airway owing to allergic rhinitis $[9,37,38]$.

Table 2 Meshing of model

\begin{tabular}{|c|c|c|}
\hline Meshed model & Meshing type & Number of elements \\
\hline & Coarse & $6,072,337$ \\
\hline & Medium & $7,814,330$ \\
\hline & Fine & $8,755,534$ \\
\hline
\end{tabular}


Table 3 Geometrical comparisons of 3D models

Standardized female adult by Lee et al. [31]

For better observations, the comparisons are focused on four different cross-sectional areas: vestibule, nasal valve, middle turbinate, and nasopharynx. To demonstrate the differences due to septal deviation and allergic rhinitis, the cross-sectional areas at different planes of both models were compared and are presented in Table 4.

In general, the standardized model by Lee et al. [31] exhibits a higher cross-sectional area than the patient's model. On average, the patient's model is 58\% smaller than the standardized model. The percentage differences in each plane ranges from $53 \%$ to $63 \%$, which indicates that the patient's model is smaller in size than that of the standardized model. As presented in Fig. 2, both models exhibit a similar trend in their cross-sectional areas. In addition, the smallest and largest crosssectional areas of both models are at their nasal valve and middle turbinate, respectively.

To obtain a more accurate figure that demonstrates the apparent differences between both models, the volume of each model was also calculated. The volume of the patient's model is $23.71 \mathrm{~cm}^{3}$, whereas that of the standardized model is $45.23 \mathrm{~cm}^{3}$. Therefore, the volume of the patient's model is $48 \%$ smaller than that of the standardized model. The cross-sectional area and volume results are relatively similar to the patient's model, which is approximately half the size of the standardized model.

\section{Pressure}

To prevent diseases and determine their treatment methods, it is necessary to understand the breathing mechanism $[39,40]$. In several studies, the pressure of airways is conventionally measured as a function of time at the domain exit $[40,41]$. Therefore, a computational analysis was performed on the patient's 3D nasal model, and the pressure drop was calculated for mass flow rates ranging from 100 to $425 \mathrm{~mL} / \mathrm{s}$. The pressure obtained for this part is the pressure relative to the atmospheric pressure. Here, negative pressure indicates human breathing with a pressure lower than atmospheric pressure. The pressure drop across the nasal cavity, from the model inlet to its outlet, was obtained, as illustrated in Fig. 2.

The inlet pressure increased drastically as the mass flow rate increased, whereas the outlet pressure

Table 4 Comparison between cross-sectional areas at different planes of both models

\begin{tabular}{llll}
\hline Plane & \multicolumn{2}{c}{ Cross-sectional area $\left.\mathbf{( c m}^{\mathbf{2}}\right)$} & Percentage difference \\
\cline { 2 - 4 } & Standardized model by Lee et al. [31] & Patient's model & \\
\hline Inlet & 0.34872949 & 0.15066816 & $57 \%$ \\
Vestibule & 0.35425289 & 0.15388511 & $57 \%$ \\
Nasal valve & 0.29106226 & 0.13621432 & $53 \%$ \\
Middle turbinate & 0.64515747 & 0.26335791 & $59 \%$ \\
Nasopharynx & 0.54266273 & 0.19838503 & $63 \%$ \\
Outlet & 0.35474969 & 0.16834382 & $53 \%$ \\
Average & 0.422769088 & 0.178475725 & $58 \%$ \\
\hline
\end{tabular}




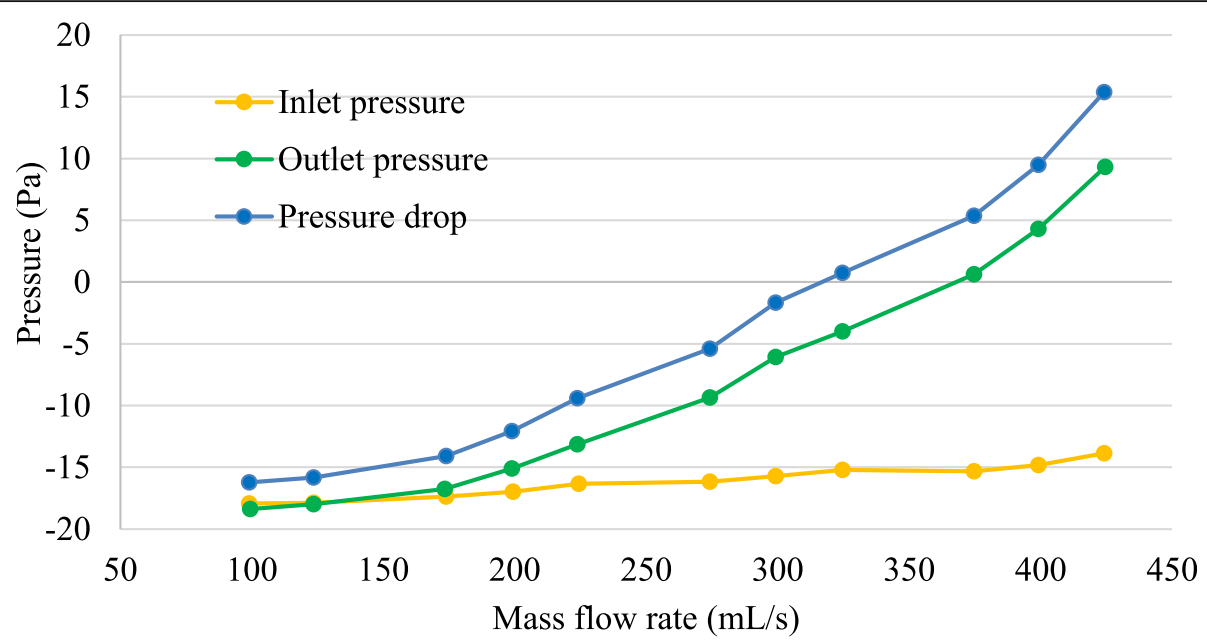

Fig. 2 Graph of pressure drop against mass flow rate

remained constant at different mass flow rates. From the obtained graph, it can be observed that the pressure drop increases gradually as the mass flow rate increases. The pressure difference induces different local flow rates and wall shear stress distributions, thus triggering further local dynamics [41, 42]. To observe the pressure changes throughout the nasal airway, the pressures at different planes and different mass flow rates are obtained, as presented in Fig. 3.

The graph shows that the pressure drop increases steadily throughout the nasal airway owing to the wall shear stress $[41,42]$. The wall shear stress during inspiration was predominantly higher in the anterior region than in other regions [43]. After a mass flow rate of $250 \mathrm{~mL} / \mathrm{s}$, the pressure change increases drastically, and some researchers have stated that a mass flow rate of less than $250 \mathrm{~mL} / \mathrm{s}$ is defined as laminar airflow. In comparison, a mass flow rate higher than $250 \mathrm{~mL} / \mathrm{s}$ is considered turbulent airflow [25, 43, 44]. The resistance in the airways triggers a pressure drop. Airway resistance is due to the flow triggered by frictional forces. It is defined as the ratio of the driving pressure to the airflow rate.

Resistance to airflow in the airways depends on (1) the flow (laminar or turbulent flow), (2) dimensions of the airway, and (3) viscosity of the gas [39]. Therefore, pressure drops climactically at the turbulent flow. It is also apparent that the pressure continues to drop from the inlet to the outlet at the same flow rate. Inlet pressure is always the highest pressure, followed by pressures at the vestibule, nasal valve, middle turbinate, nasopharynx, and finally, the nasal outlet, which has the lowest pressure. The pressure contour obtained from the side view in Table 5 depicts the pressure distribution for both laminar and turbulent flows.

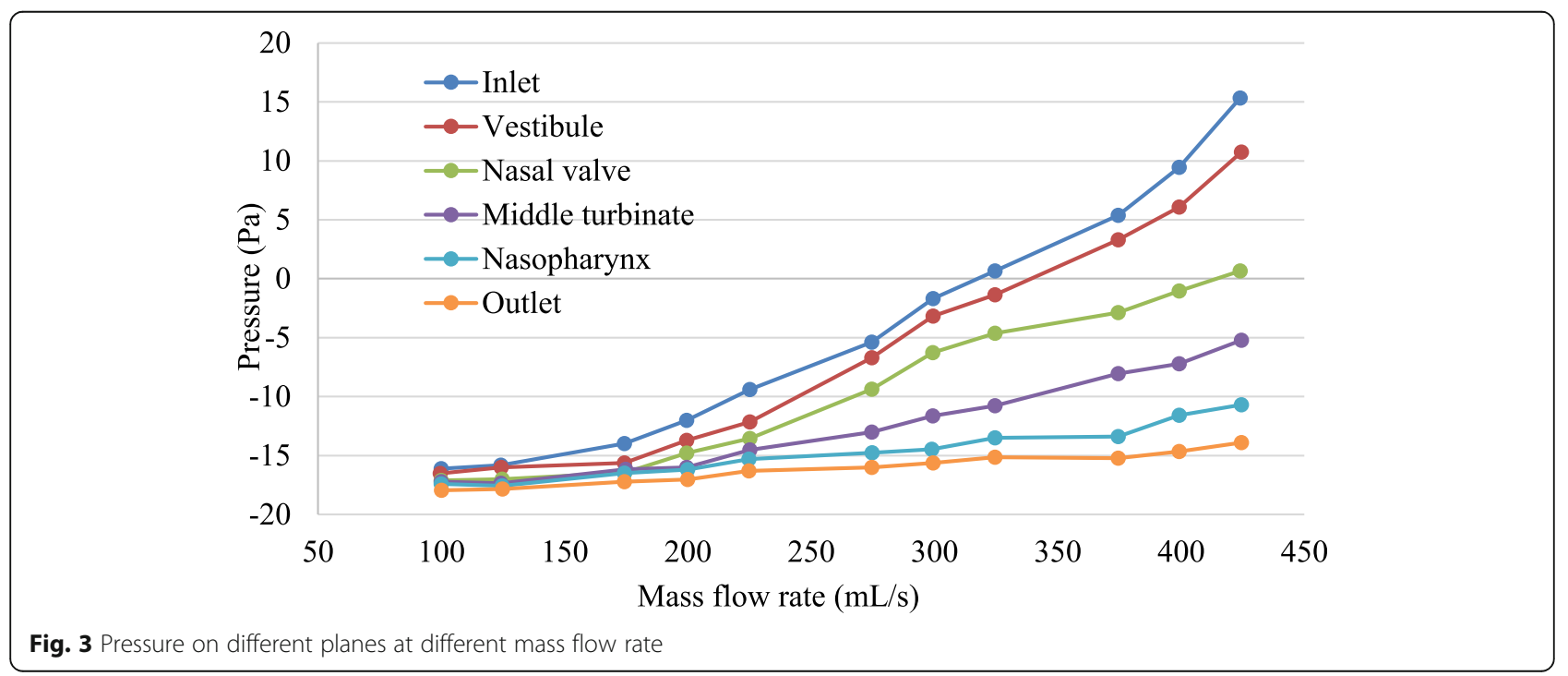


Table 5 Side view pressure contour for both laminar and turbulent flows

\begin{tabular}{lll}
\hline Mass flow rate & $\mathbf{1 2 5} \mathbf{~ m L} / \mathbf{s}$ & $\mathbf{4 0 0} \mathbf{~ m L} / \mathbf{s}$ \\
\hline Type of flow & Laminar & Turbulent \\
$+1.17 \mathrm{e}+01$ & & \\
$+0.98 \mathrm{e}+01$ & & \\
$+0.82 \mathrm{e}+01$ & & \\
$+0.73 \mathrm{e}+01$ & & \\
$+0.69 \mathrm{e}+01$ & & \\
$+0.55 \mathrm{e}+01$ & & \\
$+0.46 \mathrm{e}+01$ & & \\
$+0.37 \mathrm{e}+01$ & \\
$+0.04 \mathrm{e}+01$ & \\
$-0.50 \mathrm{e}+01$ & \\
$-0.61 \mathrm{e}+01$ & \\
$-0.74 \mathrm{e}+01$ & \\
$-0.84 \mathrm{e}+01$ & \\
$-0.94 \mathrm{e}+01$ & \\
$-1.05 \mathrm{e}+01$ & \\
$-1.18 \mathrm{e}+01$ & \\
$-1.24 \mathrm{e}+01$ & \\
$-1.38 \mathrm{e}+01$ & \\
$-1.47 \mathrm{e}+01$ & \\
$-1.52 \mathrm{e}+01$ & \\
$-1.61 \mathrm{e}+01$ & \\
\hline
\end{tabular}

\section{Velocity}

The magnitude of velocity between the patient's model and the standardized model by Lee et al. [31] were compared at different planes. The velocity magnitude of the models at the same mass flow rate, $125 \mathrm{~mL} / \mathrm{s}$, is presented with percentage differences in Table 6 , and plotted as a graph to demonstrate the velocity characteristics of the patient model. The results obtained are also presented in Table 6.

In general, the velocity magnitude of the patient's model is significantly higher than that of the standardized model, with percentage differences ranging from $70 \%$ to $128 \%$, and an average of $99 \%$ higher velocity than the standardized model. The lowest differences in velocity for both models are at the middle turbinate. Therefore, septal deviation and allergic rhinitis had the least effect on the middle turbinate.

However, the highest velocity difference occurs at the nasopharynx, which cleans the inspired air of pollutant particles and protects the delicate lower respiratory tract. Therefore, a high velocity at this plane does not cause any inconvenience to the patient [45]. From the graph, it is evident that both models have the same velocity characteristics throughout the inhalation process. Both models exhibit their highest and lowest velocities at the nasal valve and middle turbinate, respectively.

The primary function of the nasal valve is to limit the amount of airflow generated in the nasal cavity and to converge the flow. Therefore, the nasal valves always require a high velocity before the separate airflows converge from two to one. Because the middle turbinate has the largest surface area, it decreases the erectile and vascular tissue density, and is less prominent in nasal airflow patterns. Therefore, the middle turbinates always have the lowest air velocity magnitude throughout the nasal cavity [46].

To observe the differences in velocity distribution for both laminar and turbulent flows, the velocity contour and velocity vector of the side view for both airflow types are presented in Table 7. The model for the turbulent flow distribution exhibits a higher radial flow after the middle turbinate than the model for the laminar flow

Table 6 Comparison between velocity magnitude at different planes at $125 \mathrm{~mL} / \mathrm{s}$

\begin{tabular}{llll}
\hline Planes & \multicolumn{2}{l}{ Velocity magnitude $(\mathrm{m} / \mathbf{s})$} & \multirow{2}{*}{ Percentage different } \\
\cline { 2 - 4 } & Standardized model by Lee et al. [31] & Patient's model & $-105 \%$ \\
\hline Inlet & 0.38773257 & 0.796214 & $-89 \%$ \\
Vestibule & 0.35802209 & 0.675221 & $-109 \%$ \\
Nasal valve & 0.42031079 & 0.880186 & $-70 \%$ \\
Middle turbinate & 0.19572208 & 0.331966 & $-128 \%$ \\
Nasopharynx & 0.25819995 & 0.589943 & $-82 \%$ \\
Outlet & 0.35236112 & 0.642273 & $-99 \%$ \\
Average & 0.328724767 & 0.652633833 & \\
\hline
\end{tabular}


Table 7 Side view of velocity contour and vector for both laminar and turbulent flows

\begin{tabular}{|c|c|c|c|}
\hline Mass flow rate & Type of flow & Side view of velocity contour & \\
\hline $125 \mathrm{~mL} / \mathrm{s}$ & Laminar & 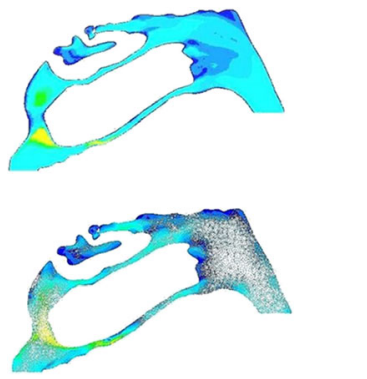 & 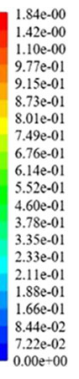 \\
\hline $400 \mathrm{~mL} / \mathrm{s}$ & Turbulent & & 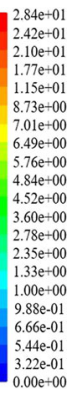 \\
\hline
\end{tabular}

distribution. This verifies that there are significant differences in the velocity pattern characteristics for both laminar and turbulent flows.

The flow distributions for both laminar and turbulent flows are almost the same at the beginning. However, differences emerge after the middle turbinate, as it has the most complex structure throughout the nasal cavity. Vortices occur after the middle turbinate because the middle and inferior turbinates are crucial structures for filtration and are used to enhance heating and humidification, when the mucosal wall surface area is enlarged [47].

The velocity vectors and contours are presented in Table 7 to compare the differences between the laminar and turbulent flows of $125 \mathrm{~mL} / \mathrm{s}$ and $400 \mathrm{~mL} / \mathrm{s}$, respectively. Both models exhibit similar patterns of velocity contours, with significant differences in velocity magnitudes. The higher mass flow rate of the turbulent flow increases the magnitudes of velocity observed along the nasal cavity. However, the nasal valve usually has the highest velocity magnitude for both laminar and turbulent flows. Simultaneously, this validates the role of the nasal valve in converging airflow from two to one, as well as that of the middle turbinate in heating and humidifying the air owing to the increase in the surface area of the meatus regions [47].

The velocity contour was considered for comparison. It clearly illustrates the physical differences between both models, as it presented 2D velocity fields in planes parallel to the flow pattern throughout the nasal cavity $[41,48]$. The airflow through each of these regions was computed by integrating the axial component of the velocity with the coronal cross-section. These flow volumes were used to estimate the relative flow allocation within each cross-section region as a percentage of the total volumetric flow for that cross-section [49]. Considering the steady airflow, sequentially recorded data could be used to determine the location of errors with magnitudes relative to their respective velocity vectors $[41,50]$. It is necessary to ensure a no-slip condition at all solid boundaries, which means that the contour plots must be zero at all physical limitations [41, 48]. A comparison between the velocity contours at a mass flow rate of 125 $\mathrm{mL} / \mathrm{s}$ is presented in Table 8 .

The velocity distribution inside the airway can be observed from the obtained velocity contours $[31,51]$. The velocity of the airflow and its spatial and temporal variations close to the wall, as well as corresponding shear rate or shear stress at the wall are essential factors necessary for several physiological processes, such as the pressure drop throughout the nose, particle deposition, and exchange processes at the wall $[16,51,52]$. Wall shear has also been identified as a putative agent for the mechano-transduction between the airflow and nasal epithelium [52, 53].

The standardized model has an excellent oval shape for both the vestibule and nasal valve; however, the patient's model has an irregular and inconsistent shape. The shape irregularity at the septal deviation caused the air to enter unevenly. The middle turbinate of the standardized model is almost symmetrical on the left and right sides, and it has a broader airway. However, the middle turbinate of the patient 
Table 8 Comparison of velocity contours at mass flow rate $125 \mathrm{~mL} / \mathrm{s}$

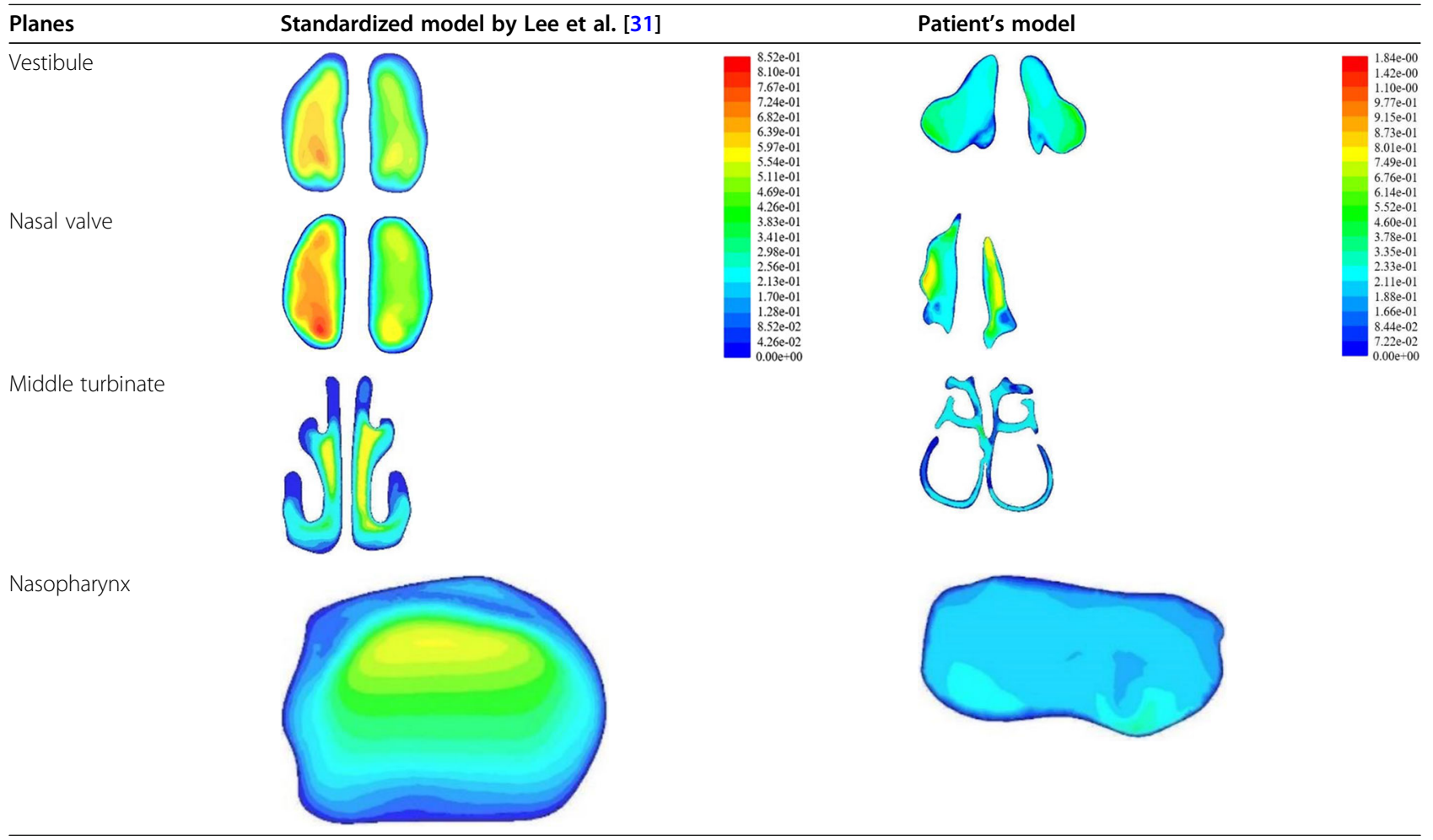

model is narrower and unsymmetrical compared to the standardized model. This irregularity is due to the airway's growth towing to allergic rhinitis, which reduces the patient's nasal airway $[9,15]$. The velocity of the standardized model ranged from 0 to $0.852 \mathrm{~m} /$ $\mathrm{s}$, whereas that of the patient's model ranged from 0 to $1.84 \mathrm{~m} / \mathrm{s}$. The standardized model has a smaller range in velocity than the patient's model, as it has a broader airway, while the patient's model has overall higher velocity magnitudes than the standardized model, during breathing.

\section{Discussion}

A summary of clinical implications and translations for this nasal airflow study is presented in Table 9. Therefore, using the 3D reconstruction model with airflow analysis as presented in this paper, specialists can see a clear picture of patients' bodies, enabling a better understanding of the condition, which helps foresee a patient's body responds to illness treatment. Moreover, these 3D reconstruction models are useful in the rapid prototyping technology of modified anatomical implants and demonstrate multiple abnormalities requiring an additional diagnostic value. The outcome of the study may also minimize disease risk through preventive medicine and conventional drug therapies.

\section{Conclusions}

In conclusion, a 3D nasal cavity model of a female adult patient with septal deviation and allergic rhinitis was developed. The airflow characteristics owing to septal deviation and allergic rhinitis were investigated and studied by analyzing the airflow simulation results using ANSYS Fluent. The developed model for the patient is approximately half the size of the standardized model; hence, its velocity is approximately two times higher than that of the standardized model during inspiration. Comparisons were carried out to study the impact of septal deviation and allergic rhinitis on the patient's nasal airflow. The standardized model with a smoother and wider airway exhibited a better velocity distribution during breathing than the patient's model. In contrast, the patient's model with growth blockage had an asymmetrical and narrow airway, thereby causing the patient's breathing to be higher in velocity than that of the healthy standardized model, at the same mass flow rate. Using the presented model, specialists can understand the human form in three dimensions, which allows them to predict how the body will respond to illness better. Furthermore, these $3 \mathrm{D}$ reconstruction models can be used in the rapid prototyping of modified anatomical implants and can show multiple abnormalities, which adds to the diagnostic value. The study's findings may also help to reduce 
Table 9 A summary of clinical implications

\begin{tabular}{|c|c|c|}
\hline Division & $\begin{array}{l}\text { Standardized model by Lee et al. } \\
\text { [31] }\end{array}$ & Patient's model \\
\hline $\begin{array}{l}\text { Nasal airway } \\
\text { surface }\end{array}$ & A smooth and clean airway & $\begin{array}{l}\text { Lots of creases on the surface as there are many growths in the nasal airway due to allergy } \\
\text { rhinitis; } \\
\text { Many disconnections that lead to difficulties in breathing. }\end{array}$ \\
\hline \multirow{2}{*}{$\begin{array}{l}\text { Cross- } \\
\text { sectional } \\
\text { areas }\end{array}$} & Good nasal cross-sectional areas & Averagely 58\% smaller cross-sectional areas than the standardized model. \\
\hline & \multicolumn{2}{|c|}{ Smallest cross-sectional area at the nasal valve and the largest cross-sectional area in the middle turbinate. } \\
\hline Volume & Good nasal volume & Forty-eight percent less volume than the standardized model \\
\hline $\begin{array}{l}\text { Nasal } \\
\text { pressure }\end{array}$ & \multicolumn{2}{|c|}{$\begin{array}{l}\text { Pressure drop increases gradually throughout the nasal airway due to the wall shear stress; } \\
\text { Wall shear stress during inspiration is predominantly higher in the anterior region; } \\
\text { Inlet pressure has always been the highest, followed by the vestibule, nasal valve, middle turbinate, nasopharynx, and finally, the nasal } \\
\text { outlet with the lowest pressure. }\end{array}$} \\
\hline \multirow[t]{2}{*}{ Velocity } & Good nasal velocity magnitude & $\begin{array}{l}\text { The patient's model's overall velocity magnitude is much higher than the standardized } \\
\text { model, ranged from } 70 \% \text { to } 128 \% \text { of differences and have an average of } 99 \% \text { higher velocity } \\
\text { than the standardized model; } \\
\text { Septal deviation and allergy rhinitis cause the least effect on the middle turbinate; } \\
\text { High velocity at the nasopharynx does not cause any inconvenience for the patient. }\end{array}$ \\
\hline & \multicolumn{2}{|c|}{$\begin{array}{l}\text { The lowest differences in velocity are at the middle turbinate; } \\
\text { The highest velocity difference occurs at the nasopharynx to clean the inspired air of pollutant particles and protect the delicate lower } \\
\text { respiratory tract. }\end{array}$} \\
\hline $\begin{array}{l}\text { Velocity } \\
\text { contour }\end{array}$ & \multicolumn{2}{|c|}{$\begin{array}{l}\text { The flow distributions for both laminar and turbulent are almost the same at the beginning; } \\
\text { Turbulent flow distribution has more radial flow after the middle turbinate. }\end{array}$} \\
\hline Shape & $\begin{array}{l}\text { Excellent oval shape for both the } \\
\text { vestibule and nasal valve; } \\
\text { Middle turbinate is almost symmetry } \\
\text { for the left and right side. }\end{array}$ & $\begin{array}{l}\text { Has irregular and inconsistent shapes; } \\
\text { Shape irregularity at the septal deviation that caused the air to enter unevenly; } \\
\text { Middle turbinate is narrower and unsymmetrical. }\end{array}$ \\
\hline
\end{tabular}

\section{disease risk through preventive medicine and traditional} drug therapies.

\section{Abbreviations}

2D: Two-dimensional; 3D: Three-dimensional; ANSYS: Analysis system; CATIA: Computer aided three-dimensional interactive application; CFD: Computational fluid dynamics; CT: Computerized tomography; FLUENT: Flow oriented Logistics Upgrade for Enterprise Networks

\section{Acknowledgements}

Not applicable.

\section{Authors' contributions}

ZFL, PR, and CFL conceptualized the project; ZFL and MYM developed the methodology and modeled the work; ZFL, PR, and CFL analyzed and processed the data; ZFL, PR, and CFL contributed to the original draft preparation; ZFL, PR, MYM, and CFL simulated the patient's data; MYM, PR, and CFL supervised the study; ZFL, PR, MYM, and CFL validated the study and contributed to writing, reviewing, and editing this manuscript. The authors read and approved the final manuscript.

\section{Funding}

This research was funded by the Universiti Sains Malaysia, No. 1001/PAERO/ 814276.

\section{Availability of data and materials}

All data generated or analyzed during this study are included in this published article.

\section{Declarations}

\section{Competing interests}

The authors declare that they have no competing interests.
Author details

${ }^{1}$ School of Aerospace Engineering, Universiti Sains Malaysia, 11800 Pulau Pinang, Malaysia. ${ }^{2}$ Faculty of Engineering \& Computing, First City University College, 47800 Selangor, Malaysia. ${ }^{3}$ Advanced Medical and Dental Institute, Universiti Sains Malaysia, 11800 Pulau Pinang, Malaysia.

Received: 15 February 2021 Accepted: 27 April 2021

Published online: 20 May 2021

References

1. Hansen F, Wood DE (2013) The adrenal fatigue solution. https://adrenalfa tiquesolution.com/. Accessed 9 Apr 2021

2. Marks TN, Maddux SD, Butaric LN, Franciscus RG (2019) Climatic adaptation in human inferior nasal turbinate morphology: evidence from Arctic and equatorial populations. Am J Phys Anthropol 169(3):498-512 https://doi. org/10.1002/ajpa.23840

3. Tracy LF, Basu S, Shah PV, Frank-Ito DO, Das S, Zanation AM et al (2019) Impact of endoscopic craniofacial resection on simulated nasal airflow and heat transport. Int Forum Allergy Rhinol 9(8):900-909 https://doi.org/10.1 002/alr.22328

4. Kim SK, Heo GE, Seo A, Na Y, Chung SK (2014) Correlation between nasal airflow characteristics and clinical relevance of nasal septal deviation to nasal airway obstruction. Respir Physiol Neurobiol 192:95-101 https://doi. org/10.1016/j.resp.2013.12.010

5. Radulesco T, Meister L, Bouchet G, Varoquaux A, Giordano J, Mancini J et al (2019) Correlations between computational fluid dynamics and clinical evaluation of nasal airway obstruction due to septal deviation: an observational study. Clin Otolaryngol 44(4):603-611 https://doi.org/10.1111/ coa. 13344

6. Deviated Septum (2021). American academy of otolaryngology-head and neck surgery. https://www.entnet.org/content/deviated-septum-overview. Accessed 9 Apr 2021

7. Teixeira J, Certal V, Chang ET, Camacho M (2016) Nasal septal deviations: a systematic review of classification systems. Plast Surg Int 2016:70891237089128 https://doi.org/10.1155/2016/7089123

8. Holbrook EH, Meyers AD (2021) Disorders of taste and smell. https:// emedicine.medscape.com/article/861242-overview. Accessed 9 Apr 2021 
9. Solé D, Sakano E, Cruz AA, Pastorino A, Prado E, de Mello FCF et al (2012) III Consenso Brasileiro sobre Rinites. Braz J Otorhinolaryngol 75(6):3

10. Borojeni AAT, Garcia GJM, Moghaddam MG, Frank-Ito DO, Kimbell JS, Laud PW et al (2020) Normative ranges of nasal airflow variables in healthy adults. Int J Comput Assist Radiol Surg 15(1):87-98 https://doi.org/10.1007/s11548019-02023-y

11. Zhang Y, Zhou XD, Lou M, Gong MJ, Zhang JB, Ma RP et al (2019) Computational fluid dynamics (CFD) investigation of aerodynamic characters inside nasal cavity towards surgical treatments for secondary atrophic rhinitis. Math Probl Eng 2019:6240320-6240328 https://doi.org/1 $0.1155 / 2019 / 6240320$

12. Schoenfeld BJ, Contreras B, Tiryaki-Sonmez G, Wilson JM, Kolber MJ, Peterson MD (2015) Regional differences in muscle activation during hamstrings exercise. J Strength Cond Res 29(1):159-164 https://doi.org/10.1 519/JSC.0000000000000598

13. Kim SK, Na Y, Kim Jl, Chung SK (2013) Patient specific CFD models of nasal airflow: overview of methods and challenges. J Biomech 46(2):299-306 https://doi.org/10.1016/j.jbiomech.2012.11.022

14. Bruening J, Goubergrits L, Hildebrandt T (2016) Team 190: CFD simulation of airflow within a nasal cavity The UberCloud. https://community. theubercloud.com/wp-content/uploads/2016/09/Team-190-Jan-Bruening. pdf. Accessed 9 Apr 2021

15. Garcia GJM, Bailie N, Martins DA, Kimbell JS (2007) Atrophic rhinitis: a CFD study of air conditioning in the nasal cavity. J Appl Physiol 103(3):10821092 https://doi.org/10.1152/japplphysiol.01118.2006

16. Faramarzi M, Baradaranfar MH, Abouali O, Atighechi S, Ahmadi G, Farhadi P et al (2014) Numerical investigation of the flow field in realistic nasal septal perforation geometry. Allergy Rhinol (Providence) 5(2):70-77 https://doi. org/10.2500/ar.2014.5.0090

17. Bailie N, Hanna B, Watterson J, Gallagher G (2006) An overview of numerical modelling of nasal airflow. Rhinology 44(1):53-57

18. Lin CL, Tawhai MH, McLennan G, Hoffman EA (2009) Multiscale simulation of gas flow in subject-specific models of the human lung. IEEE Eng Med Biol Mag 28(3):25-33 https://doi.org/10.1109/MEMB.2009.932480

19. Nomura T, Ushio M, Kondo K, Kikuchi S (2018) Effects of nasal septum perforation repair on nasal airflow: an analysis using computational fluid dynamics on preoperative and postoperative three-dimensional models. Auris Nasus Larynx 45(5):1020-1026 https://doi.org/10.1016/j.anl.2018.02.006

20. Borojeni AAT, Frank-Ito DO, Kimbell JS, Rhee JS, Garcia GJM (2017) Creation of an idealized nasopharynx geometry for accurate computational fluid dynamics simulations of nasal airflow in patient-specific models lacking the nasopharynx anatomy. Int J Numer Method Biomed Eng 33(5):e2825 https://doi.org/10.1002/cnm.2825

21. Li LF, Zang HR, Han DM, Ramanathan M Jr, Carrau RL, London NR Jr (2020) Impact of a concha bullosa on nasal airflow characteristics in the setting of nasal septal deviation: a computational fluid dynamics analysis. Am J Rhinol Allergy 34(4):456-462 https://doi.org/10.1177/1945892420905186

22. Camilo AA, Amorim PHJ, Moraes TF, de S. Azevedo F, da Silva JVL (2012) Invesalius: medical image edition. Paper presented at the 1st international conference on design and processes for medical devices, West Garda Hotel, Brescia, 2-4 May 2012

23. Ruiz CP, Ruiz CF, López AC, Español CC (2005) Computational fluid dynamics simulations of the airflow in the human nasal cavity. Acta Otorrinolaringol Esp 56(9):403-410 https://doi.org/10.1016/50001-6519(05)78638-6

24. Wang DY, Lee HP, Gordon BR (2012) Impacts of fluid dynamics simulation in study of nasal airflow physiology and pathophysiology in realistic human three-dimensional nose models. Clin Exp Otorhinolaryngol 5(4):181-187 https://doi.org/10.3342/ceo.2012.5.4.181

25. Smith K (2008) CFD analysis of pressure and flow characteristics of the human nose. Dissertation, Worcester Polytechnic Institute

26. Farzal Z, Del Signore AG, Zanation AM, Ebert JC Jr, Frank-Ito D, Kimbell JS et al (2019) A computational fluid dynamics analysis of the effects of size and shape of anterior nasal septal perforations. Rhinology 57(2):153-159 https:// doi.org/10.4193/Rhin18.111

27. Zubair M, Abdullah MZ, Ahmad KA (2013) Hybrid mesh for nasal airflow studies. Comput Math Methods Med 2013:727362-727367 https://doi.org/1 $0.1155 / 2013 / 727362$

28. Cheng YS, Yeh HC, Guilmette RA, Simpson SQ, Cheng KH, Swift DL (1996) Nasal deposition of ultrafine particles in human volunteers and its relationship to airway geometry. Aerosol Sci Technol 25(3):274-291 https:// doi.org/10.1080/02786829608965396
29. Mylavarapu G, Murugappan S, Mihaescu M, Kalra M, Khosla S, Gutmark E (2009) Validation of computational fluid dynamics methodology used for human upper airway flow simulations. J Biomech 42(10):1553-1559 https:// doi.org/10.1016/j.jbiomech.2009.03.035

30. Wen J, Inthavong K, Tu JY, Wang SM (2008) Numerical simulations for detailed airflow dynamics in a human nasal cavity. Respir Physiol Neurobiol 161(2):125-135 https://doi.org/10.1016/j.resp.2008.01.012

31. Lee CF, Abdullah MZ, Ahmad KA, Shuaib IL (2013) Standardization of malaysian adult female nasal cavity. Comput Math Methods Med 2013: 519071-519011 https://doi.org/10.1155/2013/519071

32. Lee KB, Jeon YS, Chung SK, Kim SK (2016) Effects of partial middle turbinectomy with varying resection volume and location on nasal functions and airflow characteristics by CFD. Comput Biol Med 77:214-221 https://doi.org/10.1016/j.compbiomed.2016.08.014

33. Frank-Ito DO, Kimbell JS, Borojeni AAT, Garcia GJM, Rhee JS (2019) A hierarchical stepwise approach to evaluate nasal patency after virtual surgery for nasal airway obstruction. Clin Biomech 61:172-180 https://doi. org/10.1016/j.clinbiomech.2018.12.014

34. Li C, Sun XZ, Zhao M, Yu S, Huang Q, Zhang XQ et al (2019) Comparison of airflow characteristics after Draf III frontal sinus surgery and normal person by numerical simulation. Math Biosci Eng 16(4):1750-1760 https://doi.org/1 0.3934/mbe.2019084

35. Hildebrandt T, Brüning JJ, Schmidt NL, Lamecker H, Heppt W, Zachow S et al (2019) The healthy nasal cavity-characteristics of morphology and related airflow based on a statistical shape model viewed from a surgeon's perspective. Facial Plast Surg 35(1):9-13 https://doi.org/10.1055/s-0039-1677721

36. Dilek F, Ozkaya E, Gultepe B, Yazici M, Iraz M (2016) Nasal fluid secretory immunoglobulin a levels in children with allergic rhinitis. Int J Pediatr Otorhinolaryngol 83:41-46 https://doi.org/10.1016/j.ijporl.2016.01.018

37. Hamerschmidt R, Hamerschmidt R, Moreira ATR, Tenorio SB, Timi JRR (2016) Comparison of turbinoplasty surgery efficacy in patients with and without allergic rhinitis. Braz J Otorhinolaryngol 82(2):131-139 https://doi.org/10.101 6/j.bjorl.2015.10.010

38. Kutlug S, Gunbey E, Sogut A, Celiksoy MH, Kardas S, Yildirim U et al (2016) Evaluation of olfactory function in children with allergic rhinitis and nonallergic rhinitis. Int J Pediatr Otorhinolaryngol 86:172-176 https://doi. org/10.1016/j.jporl.2016.04.038

39. Chovancová M, Elcner J (2014) The pressure gradient in the human respiratory tract. EPJ Web Conf 67:02047 https://doi.org/10.1051/epjconf/2 0146702047

40. Kim JH, Roberge RJ, Powell JB, Shaffer RE, Ylitalo CM, Sebastian JM (2015) Pressure drop of filtering facepiece respirators: how low should we go? Int J Occup Med Environ Health 28(1):71-80 https://doi.org/10.13075/ijomeh.1 896.00153

41. Lee JH, Na Y, Kim SK, Chung SK (2010) Unsteady flow characteristics through a human nasal airway. Respir Physiol Neurobiol 172(3):136-146 https://doi.org/10.1016/j.resp.2010.05.010

42. Rapoport D, Norman R, Nielson M (2001) Nasal pressure airflow measurement. https://studylib.net/doc/18755900/nasal-pressure-aiflow-mea surement. Accessed 9 Apr 2021

43. Riazuddin VN, Zubair M, Abdullah MZ, Ismail R, Shuaib IL, Hamid SA et al (2011) Numerical study of inspiratory and expiratory flow in a human nasal cavity. J Med Biol Eng 31(3):201-206 https://doi.org/10.5405//mbe.781

44. Lee CF, Abdullah MZ, Ahmad KA, Shuaib IL (2014) Analytical comparisons of standardized nasal cavity. J Med Imaging Health Inf 4(1):14-20 https://doi. org/10.1166/jmihi.2014.1214

45. Li HF, Tian ZF, Tu JY, Yang W, Yeoh GH, Xue CL et al (2006) Studies of aiflow through a human nasopharynx and pharynx airway. In: Abstracts of the 5th international conference on CFD in the process industries, CSIRO, Melbourne, 13-15 December 2006

46. Cook PR, Begegni A, Bryant WC, Davis WE (1995) Effect of partial middle turbinectomy on nasal aifflow and resistance. Otolaryngol Head Neck Surg 113(4):413-419 https://doi.org/10.1016/S0194-5998(95)70078-1

47. Wen J, Inthavong K, Tian ZF, Tu JY, Xue CL, Li CG (2007) Airflow patterns in both sides of a realistic human nasal cavity for laminar and turbulent condition. In: Abstracts of the 16th Australasian fluid mechanics conference, School of Engineering, the University of Queensland, Brisbane, 3-7 December 2007

48. Garcia GJM, Hariri BM, Patel RG, Rhee JS (2016) The relationship between nasal resistance to airflow and the airspace minimal cross-sectional area. J Biomech 49(9):1670-1678 https://doi.org/10.1016/j.jbiomech.2016.03.051 
49. Segal RA, Kepler GM, Kimbell JS (2008) Effects of differences in nasal anatomy on aiflow distribution: a comparison of four individuals at rest. Ann Biomed Eng 36(11):1870-1882 https://doi.org/10.1007/s10439-008-9556-2

50. Kelly JT, Prasad AK, Wexler AS (2000) Detailed flow patterns in the nasal cavity. J Appl Physiol 89(1):323-337 https://doi.org/10.1152/jappl.2000.89.1.323

51. Doorly DJ, Taylor DJ, Schroter RC (2008) Mechanics of airflow in the human nasal airways. Respir Physiol Neurobiol 163(1-3):100-110 https://doi.org/10.1 016/j.resp.2008.07.027

52. Elad D, Wolf M, Keck T (2008) Air-conditioning in the human nasal cavity. Respir Physiol Neurobiol 163(1-3):121-127 https://doi.org/10.1016/j.resp.2 008.05.002

53. Elad D, Naftali S, Rosenfeld M, Wolf M (2006) Physical stresses at the air-wall interface of the human nasal cavity during breathing. J Appl Physiol 100(3): 1003-1010 https://doi.org/10.1152/japplphysiol.01049.2005

\section{Publisher's Note}

Springer Nature remains neutral with regard to jurisdictional claims in published maps and institutional affiliations.

\section{Submit your manuscript to a SpringerOpen ${ }^{\mathcal{O}}$ journal and benefit from:}

- Convenient online submission

- Rigorous peer review

- Open access: articles freely available online

- High visibility within the field

- Retaining the copyright to your article

Submit your next manuscript at $\boldsymbol{\nabla}$ springeropen.com 